\title{
FAKTOR YANG MEMENGARUHI KEPUASAN PASIEN PADA INSTALASI RAWAT JALAN DI RSUD MUNYANG KUTE REDELONG BENER MERIAH TAHUN 2019
}

\section{Factors Affecting Patient Satisfaction In Street Installation In Munyang Kute RSUD Redelong Bener Merry 2019}

\author{
Eriza Dinamika', Arifah Devi Fitriani², Deli Theo ${ }^{3}$
}

1Mahasiswa Pascasarjana IKM Fakultas Kesehatan Masyarakat, Institut Kesehatan Helvetia, Medan, Indonesia

2 Dosen IKM Fakultas Kesehatan Masyarakat, Institut Kesehatan Helvetia, Medan,Indonesia

3 Dosen IKM Fakultas Kesehatan Masyarakat, Institut Kesehatan Helvetia, Medan,Indonesia

*Penulis Korespondensi: erizadinamika22@gmail.com ${ }^{1}$, arifahdevifitriani@helvetia.ac.id ${ }^{2}$, delitheo.theo@yahoo.com ${ }^{3}$

\begin{abstract}
Abstrak
Kesehatan merupakan salah satu kebutuhan dasar masyarakat, maka kesehatan adalah hak bagi setiap warga masyarakat yang dilindungi oleh UndangUndang Dasar. Setiap negara mengakui bahwa kesehatan menjadi modal terbesar untuk mencapai kesejahteraan. Oleh karena itu, perbaikan pelayanan kesehatan pada dasarnya merupakan suatu investasi sumber daya manusia untuk mencapai masyarakat yang sejahtera (welfare society) dimana pemerintah mempunyai peran yang sangat besar. Rumah sakit sebagai salah satu fasilitas pelayanan kesehatan diharapkan dapat memberikan pelayanan yang efektif, dan efisien untuk memberikan informasi kesehatan yang tepat dalam pelayanan kesehatan. Tujuan penelitian ini adalah untuk mengetahui faktor yang memengaruhi kepuasan pasien pada Instalasi Rawat Jalan di RSUD Munyang Kute Redelong Tahun 2019.

Jenis penelitian menggunakan metode survey analitik dengan pendekatan Cross Sectional, Waktu penelitian ini akan dilakukan pada bulan juli sampai dengan agustus 2019, populasi adalah seluruh pasien rawat jalan, dengan teknik pengambilan sampel secara purposive sampling yaitu sebanyak 96 orang.

Hasil penelitian menunjukkan bahwa tidak ada pengaruh jenis kelamin dengan nilai $\mathrm{p}$ value 0,025 , ada pengaruh umur dengan nilai pvalue 0,020 , tidak ada pengaruh pendidikan dengan nilai pvalue 0,399 , tidak ada pengaruh dengan nilai pvalue 0,700 , tidak ada pengaruh status kepesertaan nilai pvalue 0,275 , ada pengaruh pelayanan perawat nilai pvalue 0,005 , ada pengaruh pelayanan obat nilai pvalue 0,025 , ada pengaruh pelayanan dokter nilai pvalue 0,005 , ada pengaruh pelayanan administrasi nilai pvalue 0,005, ada pengaruh fasilitas nilai pvalue 0,016 terhadap kepuasan pasien pada Instalasi Rawat Jalan di RSUD Munyang Kute Redelong Tahun 2019.

Saran peneliti kepada Rumah Sakit Munyang Kute Redelong agar lebih meningkatkan dan membenahi fasilitas yang ada di Instalasi Rawat RS Munyang Kute Redelong serta meningkatkan pealatihan untuk meningkatkan standar pelayanan minimal rumah sakit.
\end{abstract}

\section{Kata Kunci : Kepuasan, Pasien, Rumah Sakit}




\begin{abstract}
Health is one of the basic needs of society, so health is a right for every member of society which is protected by the Basic Law. Every country recognizes that health is the biggest asset to achieve prosperity. Therefore, improving health services is basically an investment in human resources to achieve a prosperous society (welfare society) in which the government has a very big role. The hospital as a health service facility is expected to provide effective and efficient services to provide accurate health information in health services. The purpose of this study was to determine the factors that influence patient satisfaction at the Outpatient Installation at Munyang Kute Redelong Hospital in 2019.

This type of research uses an analytic survey method with a Cross Sectional approach. When this research will be conducted from July to August 2019, the population is all outpatients, with a purposive sampling technique of 96 people.

The results showed that there was no influence of gender with a $\mathrm{p}$ value of 0.025 , there was an effect of age with a p-value of 0.020 , there was no effect of education with a p-value of 0.399 , there was no influence with a $\mathrm{p}$-value of 0.700 , there was no effect of membership status with a p-value of 0.275 , there was the effect of nursing service with a p-value of 0.005 , there is an effect of drug service, a p-value of 0.025 , an influence of doctor's service, a p-value of 0.005 , an influence of administrative services, a p-value of 0.005 , an effect of a facility's p-value of 0.016 on patient satisfaction in the outpatient installation at Munyang Kute Redelong Hospital. 2019.

Researchers suggest to the Munyang Kute Redelong Hospital to further improve and fix the existing facilities in the Munyang Kute Redelong Hospital Nursing Installation and to increase training to improve the minimum hospital service standards.
\end{abstract}

Keywords: Satisfaction, Patient, Hospital 
Journal of Healthcare Technology and Medicine Vol. 6 No. 2 Oktober 2020

Universitas Ubudiyah Indonesia

e-ISSN : 2615-109X

\section{PENDAHULUAN}

Kepuasan pasien tergantung pada kualitas pelayanan yang diberikan. Pengguna jasa pelayanan rumah sakit dalam hal ini pasien menuntut pelayanan yang berkualitas tidak hanya menyangkut kesembuhan dari penyakit secara fisik atau meningkatkan derajat kesehatannya, tetapi juga menyangkut kepuasan terhadap sikap, selalu tersedianya sarana dan prasarana yang memadai dan lingkungan fisik yang dapat memberikan kenyamanan. Pelayanan adalah semua upaya yang dilakukan karyawan untuk memenuhi keinginan pelanggannya dengan jasa yang akan diberikan. Pasien merupakan salah satu indikator kualitas pelayanan yang kita berikan dan kepuasan pasien adalah suatu modal untuk mendapatkan pasien lebih banyak dan untuk mendapatkan pasien yang loyal (setia)(1).

Kepuasan pasien merupakan satu elemen yang penting dalam mengevaluasi kualitas layanan dengan mengukur respon pasien setelah menerima jasa. Adanya penilaian akan jasa tersebut maka sarana pelayanan kesehatan tersebut diharapkan tetap dapat berdiri dan semakin berkembang. Peningkatan kualitas pelayanan kesehatan (2).

Salah satu upaya terhadap penguatan fasilitas kesehatan primer ini, diharapkan tenaga kesehatan yang berada di jenjang fasilitas kesehatan primer ini, harus memiliki kemampuan dan harus menguasai hal-hal terbaru mengenai prediksi, tanda, gejala, penegakan diagnosis dan penatalaksanaan komprehensif mengenai berbagai penyakit sebab dua unsur penting dalam upaya peningkatan pelayanan kesehatan adalah tingkat kepuasan pasien sebagai pengguna jasa dan pemenuhan standar pelayanan yang telah ditetapkan. Kepuasan pasien merupakan satu elemen yang penting dalam mengevaluasi kualitas layanan dengan mengukur sejauh mana respon pasien setelah menerima jasa. Dengan adanya kualitas pelayanan yang baik, akan menciptakan kepuasan bagi para pasien(3).

Salah satu penilaian kualitas pelayanan, yaitu reliability, responsiveness, dan emphaty. Reliability, yaitu kemampuan tenaga kesehatan untuk memberikan pelayanan yang dijanjikan dengan tepat waktu dan memuaskan. Responsiveness, yaitu kemampuan para tenaga kesehatan untuk membantu pasien dan memberikan pelayanan yang tanggap. Emphaty mencakup kemudahan dalam melakukan hubungan komunikasi yang baik dan memahami kebutuhan para pasien(4).

Rumah sakit sebagai salah satu fasilitas pelayanan kesehatan diharapkan dapat memberikan pelayanan yang efektif, efisien, dan dituntut untuk memberikan informasi kesehatan yang tepat dalam pelayanan kesehatan dan menghasilkan data yang akurat . Di dalam penyelenggaraan pelayanan publik, masih banyak dijumpai kekurangan, sehingga mempengaruhi kualitas pelayanan kepada masyarakat . Jika kondisi seperti ini tidak direspon, maka akan menimbulkan citra yang kurang baik terhadap rumah sakit sendiri . Mengingat jenis pelayanan yang sangat beragam, maka dalam memenuhi pelayanan diperlukan pedoman yang digunakan sebagai acuan bagi instansi di lingkungan instansi kesehatan. Pelayanan kesehatan adalah hak asasi manusia 
Journal of Healthcare Technology and Medicine Vol. 6 No. 2 Oktober 2020

Universitas Ubudiyah Indonesia

e-ISSN : 2615-109X

yang harus diselenggarakan oleh pemerintah dan swasta. Untuk mencapai kualitas yang diharapkan oleh masyarakat perlu adanya kerjasama dan usaha yang berkesinambungan (5).

Tingginya kebutuhan masyarakat akan pelayanan kesahatan tidak diimbangi dengan peningkatan pelayanan kesehatan. Kualitas pelayanan kesehatan merujuk pada tingkat kesempurnaan penampilan pelayanan kesehatan yang dapat memuaskan setiap pemakai jasa pelayanan kesehatan yang sesuai dengan tingkat kepuasan rata-rata penduduk, tata cara penyelenggaraannya yang sesuai dengan standar dan kode etik profesi yang telah ditetapkan. Untuk dapat menyelenggarakan pelayanan kesehatan dengan baik, maka banyak hal yang perlu diperhatikan diantaranya adalah kesesuaian dengan kebutuhan masyarakat, sehingga perkembangan pelayanan kesehatan secara umum dipengaruhi oleh besar kecilnya suatu kebutuhan dan tuntutan dari masyarakat yang sebenarnya merupakan gambaran dari masalah kesehatan yang dihadapi masyarakat tersebut. Adapun tuntutan kesehatan tersebut merupakan suatu hal yang subjektif, oleh karena itu pemenuhan terhadap tuntutan kesehatan sedikit pengaruhnya terhadap perubahan derajat kesehatan, karena sifatnya yang subjektif, maka tuntutan terhadap kesehatan sangat dipengaruhi oleh status sosial masyarakat itu sendiri (6).

Kepuasan merupakan perasaan senang atau kecewa yang muncul setelah membandingkan antara persepsi terhadap kinerja atau hasil suatu produk atau jasa dan harapanharapan. Dengan mengukur kepuasan pasien akan dapat diketahui mutu dari pelayanan kesehatan(7).Kualitas pelayanan yang baik akan mempengaruhi kepuasan pasien dan mengakibatkan pasien kembali datang untuk menggunakan jasa pelayanan tersebut. Pasien dapat menjadi kunci dalam mengukur kualitas pelayanan berdasarkan kepuasan mereka (8).

Rumah Sakit RSUD Munyang Kute Bener Meriah merupakan salah satu rujukan fasilitas kesehatan tingkat lanjut yang dipilih oleh pasien peserta BPJS Kesehatan yang ada di kabupaten Bener Meriah. RSUD Munyang Kute Redelongmerupakan rumah sakit tipe $\mathrm{C}$ dengan akreditasi Madya bintang tiga. RSUD Munyang Kute Redelongini melayani pasien anggota TNI, PNS, keluarga Purnawirawan, dan BPJS serta masyarakat umum.

Pada tahun 2016 kunjungan instalasi rawat jalan di RSUD Munyang Kute Redelongsebanyak 5.260 orang, kemudian meningkat pada tahun 2017 sebanyak 30.987 orang. Pada tahun 2017.

Berdasarkan studi pendahuluan yang dilakukan oleh peneliti terhadap 20 responden pasien pada instalasi rawat jalan di RSUD Munyang Kute Bener Meriah sebanyak 80\% (16 orang) menyatakan keluhan terhadap kenyamanan tempat dan waktu menunggu, diantaranya terlihat tempat duduk yang kurang bagi pasien, WC yang kotor dan kurang air, banyaknya kursi tunggu yang rusak, lamanya antrian pada bagian pendaftaran, keluhan terhadap kepuasan pada saat pendaftaran karena nomor antrian yang didapat pasien terkadang terdalului oleh pasien yang baru datang dan tampak pengambilan nomor antrian masih menggunakan kartu manual yang dibuat oleh pihak pendaftaran, minimnya informasi tata cara pendaftaran 
Journal of Healthcare Technology and Medicine Vol. 6 No. 2 Oktober 2020

Universitas Ubudiyah Indonesia

e-ISSN : 2615-109X

untuk poli klinik, sehingga pasien sering lupa tata cara pendaftaran, kurang telitinya perawat memang gil pasien tidak sesuai dengan antrian karena sistem manual, lamanya pelayanan farmasi yang hanya memiliki satu unit farmasi untuk semua poli, lamanya hasil poto yang keluar dari unit radiologi, pasien mengeluh harus datang kembali keesokan harinya untuk mendapatkan informasi bacaan hasil poto. kurangnya waktu dokter untuk konsultasi penyakit yang dialami pasien dengan alasan waktu yang singkat karena bertugas di 2 rumah sakit yang berbeda, sering telatnya dokter datang dengan alasan visit ruangan hal itu berbanding terbalik dengan tingkat kepuasan pasien yang diukur oleh pihak rumah sakit yang menyatakan bahwasanya tingkat kepuasan pasien terhadap pelayanan dokter sebesar $70 \%$. Media setempat juga telah menyoroti masalah buruknya sarana dan prasarana yang ada di Rumah Sakit Muyang Kute, Hasil studi pendahuluan tersebut menunjukkan bahwa kepuasan pasien terhadap pelayanan di instalasi rawat jalan masih rendah. Hasil tersebut menunjukkan bahwa adanya malasah kepuasan pada pasien terhadap pelayanan pada instalasi rawat di RSUD Munyang Kute Redelong.

Rumusan masalah dalam penelitian ini adalah untuk mengetahui apakah faktor yang memengaruhi kepuasan pasien pada instalasi rawat jalan di RSUD Munyang Kute Bener Meriah tahun 2019.

Tujuan penelitian adalah untuk mengetahui faktor yang memengaruhi kepuasan pasien pada Instalasi Rawat Jalan di RSUD Munyang Kute Redelong Tahun 2019.

\section{METODE PENELITIAN}

Jenis penelitian menggunakan penelitian kuantitatif metode survey analitik dengan pendekatan Cross Sectional.

Penelitian ini dilakukan di Rumah Sakit Umum Daerah Munyang Kute Redelong Bener Meriah. Alasan pemilihan lokasi penelitian ini karena di temukan pasien-pasien yang mengeluh dan mengalami masalah terhadap kepuasan pelayanan yang di peroleh dari rumah sakit tersebut.Waktu penelitian ini dilakukan pada tanggal 27 juli sampai 29 agustus2019. Populasi dalam penelitian ini adalah seluruh pasien rawat jalan di rumah sakit umum Munyang kute bener meriah dengan jumlah 2.582 orang. Sampel dalam penelitian ini adalah pasien yang berkunjung di rawat jalan rumah sakit munyang kute bener meriah sebanyak 96 orang.

\section{HASIL DAN PEMBAHASAN}

1. Pengaruh Jenis Kelamin Terhadap Kepuasaan Pasien 
Journal of Healthcare Technology and Medicine Vol. 6 No. 2 Oktober 2020

Universitas Ubudiyah Indonesia

e-ISSN : 2615-109X

Hasil penelitian menunjukkan bahwa 70 responden (72,9\%) yang memiliki jenis kelamin perempuan paling banyak tidak puas sebanyak 49 responden $(51,0 \%)$ dan dari 21 responden $(21,9 \%)$, yang memiliki jenis kelamin laki-laki paling banyak tidak puas sebanyak 15 responden $(15,6 \%)$ dan yang puas sebanyak 11 orang $(11,5 \%)$. Hasil analisis chi-square menunjukkan bahwa nilai probabilitasnya $(0,256)>$ sig_ $\alpha=0,05$.

Berdasarkan pengamatan peneliti di instalasi rawat jalan RSUD Munyang Kute Redelong tahun 2019 diketahui bahwa tidak terlihat ketidakpuasan pasien terhadap laki-laki atau perempuan, akan tetapi ketidakpuasan perempuan sedikitlebih tampak dari pada laki-laki dan tidak terlalu mendominasi, hal itu terlihat dari seringnya pasien berjenis kelamin perempuan bertanya mengenai nomor antrian, sering menuangkan keluh kesahnya kepada peneliti terhadap kepuasan pelayanan yang diberikan rumah sakit tersebut dan peneliti menyimpulkan bahwa perempuan lebih terbuka terhadap pelayanan yang diperoleh dibandingkan dengan laki-laki, misalnya adalah ketika seorang pasien perempuan menunggu lama atau mendapat antrian lama maka pasien tersebut akan langsung menyampaikan dan bahkan menunjukkan ketidak senagan terhadap pelayanan tersebut, sedangkan laki-laki tidak akan ribut dan tidak menunjukkan sikap yang tidak senang.

\section{Pengaruh Umur Terhadap Kepuasaan Pasien}

Hasil penelitian menunjukkan bahwa dari 25 responden (26,0\%) yang memiliki umur 15-24 tahun paling banyak tidak puas sebanyak 22 responden (22,9\%), dari 46 responden (47,9\%) yang memiliki umur 25-40 tahun paling banyak tidak puas sebanyak 29 responden (30,2\%) dan dari 25 responden $(26,0 \%)$ yang memiliki umur >40 tahun paling banyak tidak puas sebanyak 13 responden (13,5\%). Dari hasil analisis chisquare nilai probabilitasnya $(0,020)<\operatorname{sig} \_\alpha=0,05$ yang artinya ada pengaruh umur dengan kepuasan pasien.

Usia akan mempengaruhi pengetahuan yang dimiliki oleh seseorang yang nantinya dapat mempengaruhi pengambilan keputusan untuk status kesehatannya (9). Hubungan antara umur dan kepuasan terdapat perbedaan kepuasan antara umur muda dengan umur tua Menurut Rahman (2006) menyatakan bahwa kepuasan berdasarkan umur produktif dan umur produktif mempunyai tuntutan dan harapan yang lebih besar dibandingkan umur tua.

3. Pengaruh Pendidikan Terhadap Kepuasaan Pasien

Hasil penelitian menunjukkan bahwa 18 responden (18,8\%) yang memiliki pendidikan lulusan SD paling banyak tidak puas sebanyak 14 responden $(14,6 \%)$, dari 33 responden $(34,4 \%)$ yang memiliki pendidikan lulusan SMP paling banyak tidak puas sebanyak 23 responden (24,0\%), dari 31 responden $(32,3 \%)$ yang memiliki pendidikan lulusan SMA paling banyak tidak puas sebanyak 20 responden $(20,8 \%)$ dan dari 14 responden $(14,6 \%)$ yang memiliki pendidikan lulusan PT mempunyai tingkat kepuasan yang 
Journal of Healthcare Technology and Medicine Vol. 6 No. 2 Oktober 2020

Universitas Ubudiyah Indonesia

e-ISSN : 2615-109X

sama dan tingkat ke tidakpuasan yang sama yaitu sebanyak 7 responden( 7,3$)$ yang puas dan 7 responden $(7,3)$ yang tidak puas. Dari hasil analisis chi-square nilai probabilitasnya $(0,399)>\operatorname{sig} \_\alpha=0,05$.

Menurut Mar'at perasaan puas pada setiap individu tidaklah sama, akan tetapi ungkapan puas pada sekelompok individu dapat terjadi hampir sama karena adanya pengaruh lingkungan dan masyarakat golongan tertentu Seperti halnya yang dikemukaan oleh Azrul Azwar bahwa sama halnya dengan mutu pelayanan, dimensi kepuasan pasien sangatlah bervariasi. Sehingga kepuasan pasien tidak hanya dipengaruhi oleh pendidikan seseorang tetapi pada aspek lainnya.

Hubungan antara tingkat pendidikan dengan status kesehatan. Tingkat pendidikan secara tidak langsung akan mempengaruhi pengetahuan seseorang, dan berdampak pada pengambilan keputusan terhadap kesehatannya. Tingkat pendidikan adalah salah satu factor struktur sosial dapat memberikan dorongan kepada seseorang dalam mengambil tindakan untuk kesehatannya. Peserta yang berpendidikan sedang lebih puas dengan pelayanan rawat inap dibandingkan dengan berpendidikann tinggi (10).

4. Pengaruh Pekerjaan Terhadap Kepuasaan Pasien

Hasil penelitian menunjukkan bahwa dari 28 responden $(29,2 \%)$ yang bekerja sebagai IRT paling banyak tidak puas sebanyak 21 responden (21,9\%), dari 23 responden $(24,0 \%)$ yang bekerja sebagai Kuli paling banyak tidak puas sebanyak 17 responden $(17,7 \%)$, dari 31 responden $(32,3 \%)$ yang bekerja sebagai wiraswasta paling banyak tidak puas sebanyak 18 responden $(18,8 \%)$ dan dari 14 responden $(14,6 \%)$ yang bekerja sebagai PNS paling banyak tidak puas sebanyak 8 responden $(8,3 \%)$. Dari hasil analisis chi-square pada lampiran tabel uji chi-squarediketahui bahwa nilai probabilitasnya $(0,388)>\operatorname{sig} \alpha \alpha=0,05$ di RSUD Munyang Kute Redelong Tahun 2019.

Berdasarkan pengamatan peneliti diketahui bahwa pekerjaan seseoorang tidak selamanya dapat menunjukkan tingkat kepuasan masing-masing. Dari pengamatan yang di peroleh peneliti bahwa tingkat kepuasan pasien yang bekerja dan yang tidak bekerja ada yang sama, akan tetapi ada juga tingkat kepuasannya tidak sama walaupun pekerjaannya sama, hanya saja pasien yang pekerjaannya PNS lebih mudah berkomunikasi tentang kepuasan di RSUD Munyang Kute Redelong Tahun 2019.

5. Pengaruh Status Kepesertaan Terhadap Kepuasaan Pasien

Hasil penelitian menunjukkan bahwa dari dari 19 responden $(19,8 \%)$ yang status kelas I paling banyak tidak puas sebanyak 11 responden $(11,5 \%)$, dari 33 responden $(34,4 \%)$ yang status kelas II paling banyak tidak puas sebanyak 20 responden $(20,8 \%)$ dan dari 44 responden $(45,8 \%)$ yang status kelas III paling banyak puas sebanyak 33 responden $(34,4 \%)$. Dari hasil analisis chi-square diketahui bahwa nilai probabilitasnya $(0,275)<\operatorname{sig} \_\alpha=0,05$.yang artinya tidak ada pengaruh status kepesertaan terhadap kepuasan pasien di RSUD Munyang Kute Redelong Tahun 2019.

6. Pengaruh Pelayanan Perawat Terhadap Kepuasaan Pasien 
Journal of Healthcare Technology and Medicine Vol. 6 No. 2 Oktober 2020

Universitas Ubudiyah Indonesia

e-ISSN : 2615-109X

Hasil penelitian menunjukkan bahwa dari 48 responden (50\%) yang mengatakan pelayanan perawat tidak baik paling banyak tidak puas sebanyak 39 responden (40,6\%) dan dari 48 responden (50\%) yang mengatakan pelayanan perawat baik paling banyak tidak puas sebanyak 25 responden (26\%). Dari hasil analisis chi-square diketahui bahwa nilai probabilitasnya $(0,005)<\operatorname{sig} \_\alpha=0,05$ yang artinya ada pengaruh pelayanan perawat terhadap kepuasan pasien di RSUD Munyang Kute Redelong Tahun 2019.

Berdasarkan pengamatan peneliti diketahui bahwa pelayanan perawat sangat mempengaruhi kepuasan pasien, karena perawat adalah salah satu petugas yang sering bertemu dengan pasien, di Instalasi rawat jalan RSUD Munyang Kute Redelong Bener Meriah terlihat beberapa perawat kurang dalam segi kerapian, kurang komunikasi yang baik kepada pasien, dan beberapa perawat ada yang kurang memberikan senyum dan sapaan kepada pasien, mungkin disebabkan banyaknya pasien yang berkunjung dan factor kelelahan. Sehingga pelayanan yang diberikan kurang maksimal terhadap pasien yang berkunjung diinstalai Rawat jalan RSUD Munyang Kute Redelong Tahun 2019.

7. Pengaruh Pelayanan Obat Terhadap Kepuasaan Pasien

Hasil penelitian menunjukkan bahwa dari 48 responden (50\%) yang mengatakan pelayanan obat tidak baik paling banyak tidak puas sebanyak 39 responden (40,6\%) dan dari 46 responden $(57,9 \%)$ yang mengatakan pelayanan perawat baik paling banyak tidak puas sebanyak 25 responden (26\%). Dari hasil analisis chi-square pada lampiran tabel uji chi-square diketahui bahwa nilai probabilitasnya $(0,025)<$ sig_ $\alpha=0,05$ yang artinya ada pengaruh pelayanan obat terhadap kepuasan pasien di RSUD Munyang Kute Redelong Tahun 2019.

Kegiatan pelayanan kefarmasian yang semula hanya berfokus pada pengelolaan obat sebagai komoditi menjadi pelayanan yang komprehensif yang bertujuan untuk meningkatkan kualitashidup dari pasien. Sebagai konsekuensi perubahan orientasi tersebut, apoteker dituntut untuk meningkatkan pengetahuan, ketrampilan dan perilaku untuk dapat melaksanakan interaksi langsung dengan pasien. Bentuk interaksi tersebut antara lain pemberian informasi, monitoring penggunaan obat dan mengetahui tujuan akhirnya sesuai harapan dan terdokumentasi dengan

Berdasarkan pengamatan peneliti di poli RSUD Munyang Kute Redelong Bener Meriah diketahui bahwa pelayanan obat sangat berpengaruh terhadap kepuasan pasien, dimana pada saat pasien menerima resep pasien menunggu lama, dan petugas juga tidak menjelaskan jenis obat dan kegunaan obat yang diberikan kepada pasien petugas hanya menjelaskan cara dan waktu meminum obat dan dari pengamatan peneliti ada beberapa obat yang tidak tersedia di RSUD Munyang Kute Redelong tahun 2019 sehingga beberapa pasien diberi pengantar dan diminta untuk mengambil obat yang tidak tersedia ke RSUD Datu Beru Takengon.

8. Pengaruh Pelayanan Dokter Terhadap Kepuasaan Pasien 
Journal of Healthcare Technology and Medicine Vol. 6 No. 2 Oktober 2020

Universitas Ubudiyah Indonesia

e-ISSN : 2615-109X

Hasil penelitian menunjukkan bahwa dari 54 responden $(56,3 \%)$ yang mengatakan pelayanan dokter tidak baik paling banyak tidak puas sebanyak 43 responden (44,8\%) dan dari 42 responden (43,8\%) yang mengatakan pelayanan dokter baik sama jumlah yang puas dan tidak puas sebanyak 21 responden $(21,9 \%)$. Dari hasil analisis chi-square diketahui bahwa nilai probabilitasnya $(0,005)<\operatorname{sig} \_\alpha=0,05$.

Pelayanan Dokter merupakan pelayanan yang langsung dirasakan oleh pasien pada saat melakukan pemeriksaan. Pelayanan Dokter sangat memengaruhi pemanfaatan ulang pelayanan kesehatan.

Berdasarkan pengamatan peneliti diketahui bahwa status kepesertaan di RSUD Munyang Kute Redelong Tahu 2019 tidak terlalu berpengaruh pada tingkat kepuasan pasien, dimana pasien dengan status kepesertaan kelas III puas dengan pelayanan yang diterima, sedangkan pasien dengan status kepesertaan kelas I mayoritas puas dengan pelayanan yang diterimanya.

Penelitian Dewi tentang Analisis Mutu Pelayanan Dokter Terhadap Kepuasan pasien BPJS Sunan Kalijaga Demak menunjukkan bahwa berdasarkan mutu cepat tanggap di peroleh $69 \%$ kurang baik dan 40\% Dokter tidak merespon keluhan pasien, berdasarkan mutu kemampuan diperoleh 63\% baik dan 50\% kurang baik dengan Dokter tidak datang tepat waktu, sebagian besar berpendapat bahwa mutu pelayanan jaminan baik $96 \%$ dan $4 \%$ masih kurang baik, berdasarkan mutu pelayanan empaty dokter 57\% baik dan 43\% Dokter tidak meluangkan waktunya untuk berkomunikasi, berdasarkan mutu pelayanan secara langsung $22 \%$ baik dan kurang baik $6 \%$ tentang gedung dan berdasarkan kepuasan pasien terdapat $44 \%$ pasien menyatakan puas dan $56 \%$ menyatakan kurang puas.(11)

9. Pengaruh Pelayanan ADM Terhadap Kepuasaan Pasien

Hasil penelitian menunjukkan bahwa dari 54 responden (56,3\%) yang mengatakan pelayanan ADM tidak baik paling banyak tidak puas sebanyak 43 responden $(44,8 \%)$ dan dari 42 responden $(43,8 \%)$ yang mengatakan pelayanan ADM baik sama jumlah yang puas dan tidak puas sebanyak 21 responden $(21,9 \%)$. Dari hasil analisis chi-square diketahui bahwa nilai probabilitasnya $(0,005)<\operatorname{sig} \_\alpha=0,05$.

Berdasarkan pengamatan peneliti di RSUD Munyang Kute Redelong tahun 2019 diketahui bahwa pelayanan administrasi masih kurang maksimal, dimana peneliti mengamati bahwa bagian administrasi tidak mengarahkan dengan jelas, kurangnya keramah-tamahan petugas, kurangnya komunikasi yang baik antara petugas dan pasien dan system antrian masih menggunakan sistem manual.

\section{Pengaruh Fasilitas Terhadap Kepuasaan Pasien}

Hasil penelitian menunjukkan bahwa dari 54 responden $(56,3 \%)$ yang mengatakan fasilitas tidak baik paling banyak tidak puas sebanyak 42 responden $(43,8 \%)$ dan dari 42 responden $(43,8 \%)$ yang mengatakan 
Journal of Healthcare Technology and Medicine Vol. 6 No. 2 Oktober 2020

Universitas Ubudiyah Indonesia

e-ISSN : 2615-109X

fasilitas baik paling banyak tidak puas sebanyak 22 responden (22,9\%). Dari hasil analisis chi-square diketahui bahwa nilai probabilitasnya $(0,016)<\operatorname{sig} \_\alpha=0,0$.

Terpenuhi kualitas pelayanan bagi konsumen (pelanggan) dapat mempengaruhi kepuasan konsumen. Lengkapnya fasilitas (internal dan eksternal) berpengaruh terhadap kepuasan konsumen (pengguna ponsel). Hal ini jelas sekali bahwa konsumen akan menuntut kemudahan-kemudahan kepada pihak pemberi jasa berkenaan dengan kebutuhan yang diinginkan. Reputasi yang dimiliki oleh provider dapat mempengaruhi kepuasan konsumen (pelanggan).

Berdasarkan pengamatan peneliti di RSUD Munyang Kute Redelong tahun 2019. diketahui bahwa fasilitas di rumah sakit munyang kute bener meriah masih sangat kurang, dimana masih banyak tempat duduk yang tidak mencukupi untuk pasien terlihat dari banyaknya pasien berdiri dan duduk dilantai, terlihat toilet yang tidak bersih dan tidak tersedianya air yang cukup.

\section{KESIMPULAN DAN SARAN}

Tidak ada pengaruh jenis kelamin dengan kepuasan pasien, Ada pengaruh umur dengan kepuasan pasien, Tidak ada pengaruh pendidikan dengan kepuasan pasien, Tidak ada pengaruh pekerjaan dengan kepuasan pasien, Tidak Ada pengaruh status kepesertaan dengan kepuasan pasien, Ada pengaruh pelayanan perawat dengan kepuasan pasien, Tidak ada pengaruh pelayanan obat dengan kepuasan pasien, Ada pengaruh pelayanan Dokter dengan kepuasan pasien, Ada pengaruh pelayanan ADM dengan kepuasan pasien, Ada pengaruh fasilitas dengan kepuasan pasien.

Diharapkan kepada Rumah Sakit untuk meningkatkan pelayanan keperawatan, pelayanan obat, pelayanan dokter, administrasi pada instalasi rawat rajan RSUD Munyang Kute Redelong Bener Meriah yang adadirumah sakit Munyang Kute tersebut. Serta memberikan pelatihan khusus untu perawat, pihak administrasi dan pelayanan oba.

\section{DAFTAR PUSTAKA}

Siswati, Sri. Kualitas pelayanan kesehatan dengan kepuasan pasien Bpjs di Unit Rawat Inap RSUD Kota Makassar. Jurnal MKMI, September 2015, hal.174-183; 2015 
Abidin. Pengaruh kualitas pelayanan bpjs kesehatan terhadap kepuasan pasien di puskesmas cempae Kota Parepare. Jurnal MKMI, vol. 12 no. 2; 2016

Undang-Undang Republik Indonesia Nomor 24 Tahun 2011 tentang Badan Penyelenggara Jaminan Sosial (BPJS).

Undang - Undang Republik Indonesia Nomor 40 Tahun 2004 tentang Sistem Jaminan Sosial Nasional (SJSN).

Ulinuha, Fuzna Elsa. Kepuasan pasien BPJS (badan penyelenggara jaminan sosial) terhadap pelayanan di unit rawat jalan (URJ) Rumah Sakit Permata Medika Semarang Tahun 2014

Rarasati, Desi Hanggono. Dampak kenaikan tarif bpjs kesehatan terhadap pelayanan kesehatan di Kota Malang. Jurnal Politik Muda, Vol.6, No.1, Januari-Maret 2017, 34 - 40; 2017

Nugraheni, gesnita, dkk. Kepuasan pasien bpjs kesehatan terhadap kualitas pelayanan kefarmasian di pusat kesehatan masyarakat (analisis menggunakan servqual model dan customer window quadrant). e-ISSN : 2541-0474; 2016

Imbalo,S.P. Jaminan Mutu Layanan Kesehatan: Dasar-Dasar Pengertian dan Penerapan. Jakarta : EGC; 2006.

Suryati, dkk. Faktor-Faktor Yang Berhubungan Dengan Kepuasan Pasien BPJS Terhadap Pelayanan Rawat Jalan di Rumah Sakit Panti Wilasa Citarum Semarang: Jurnal Kesehatan Masyarakat Vol.5 No. 5; 2017

Dede, S. Kepuasan Pasien BPJS Di Pelayanan RAWAT Jalan Terhadap Waktu Tunggu Penyediaan Berkas Rekam Medis Di Rumah Sakit PKU Muhammadyah Bantul Yogyakarta; 2017

Lumenta, B.. Pelayanan Medis, Citra, Konflik dan Harapan, Penerbit Kanisius, Yogyakarta; 1998 